\title{
Piper aduncum L. (matico) utilizado como tratamiento para el daño pulmonar y Covid-19
}

\author{
Piper aduncum L. (matico) used as a treatment for lung damage and Covid-19
}

Piper aduncum L. (matico) utilizado como tratamiento para el daño pulmonar y Covid-19

\section{Franklin Ore Areche}

franklin.agroin@gmail.com

https://orcid.org/0000-0002-7168-1742

\section{Jovencio Ticsihua Huaman}

jticsihuahuaman2020@gmail.com

https://orcid.org/0000-0001-5287-4461
Alfonso Ruiz Rodríguez

alfonso.ruiz@unh.edu.pe

https://orcid.org/0000-0002-0852-5878

Denis Dante Corilla Flores

corillafdd@gmail.com

https://orcid.org/0000-0002-5233-8666

Escuela Profesional de Ingeniería Agroindustrial-Universidad Nacional de Huancavelica, Huancavelica-Perú

Recibido 16 de agosto 2021 / Arbitrado y aceptado 21 de septiembre 2021 / Publicado 14 de diciembre 2021

\section{RESUMEN}

El objetivo principal fue conocer las propiedades antimicrobianas del Piper aduncum L. (matico) para el tratamiento de prevención del Covid-19. El aceite esencial, como los extractos de las hojas y la corteza son muy valiosos como agente cicatrizante, antibacterianos y antifúngico. De esta manera los componentes los flavonoides presentes en el aceite esencial de Piper aduncum L. (matico) fortifican la conectividad de los tejidos mediante la inhibición de algunas de las enzimas que pueden hidrolizar el proteoglicano y la malla proteica, lo cual podría aumentar el efecto antibacteriano al obstaculizar la difusión de la infección al tejido, su actividad antibacterial frente a Staphylococus aureus y Echerichia coli; obteniéndose como resultado que los metabolitos secundarios como flavonoides, compuestos fenólicos, esteroides y alcaloides cuentan con acción antibacterial. La planta del Piper aduncum L. (matico) es un buen cicatrizante y antifúngico se está comercializando como producto farmacéutico en gel. La conclusión que el aceite esencial de Piper aduncum L. (matico) no ayuda a prevenir ni mucho menos a eliminar el nuevo coronavirus y su composición química del matico solo ayuda a prevenir algunas de los síntomas del Covid 19.

Palabras clave: Covid-19; Piper aduncum L.; enzima; cicatrizante; inhibición

\begin{abstract}
The main objective was to know the antimicrobial properties of Piper aduncum L. (matico) for the prevention treatment of Covid-19. The essential oil, like the extracts of the leaves and the bark, are very valuable as a healing agent, antibacterial and antifungal. In this way, the flavonoid components present in the essential oil of Piper aduncum L. (matico) fortify the connectivity of the tissues by inhibiting some of the enzymes that can hydrolyze the proteoglycan and the protein mesh, which could increase the effect antibacterial by hindering the spread of the infection to the tissue, its antibacterial activity against Staphylococus aureus and Echerichia coli; As a result, secondary metabolites such as flavonoids, phenolic compounds, steroids and alkaloids have antibacterial action. The Piper aduncum L. (matico) plant is a good healing and antifungal agent. It is being marketed as a pharmaceutical gel product. The conclusion that the essential oil of Piper aduncum L. (matico) does not help prevent, much less eliminate the new coronavirus and its chemical composition of the matico only helps prevent some of the symptoms of Covid 19.
\end{abstract}

Key words: Covid-19; Piper aduncum L.; enzyme; healing; inhibition 


\section{RESUMO}

El principal objetivo fue conocer las propiedades antimicrobianas de Piper aduncum L. (matico) para el tratamiento preventivo de Covid-19. El aceite esencial, al igual que los extractos de las hojas y la corteza, son muy valiosos como agente curativo, antibacteriano y antifúngico. De esta forma, los componentes flavonoides presentes en el aceite esencial de Piper aduncum L. (matico) fortalecen la conectividad de los tejidos al inhibir algunas de las enzimas que pueden hidrolizar el proteoglicano y la malla proteica, lo que podría incrementar el efecto antibacteriano al obstaculizar la propagación de la infección al tejido, su actividad antibacteriana contra Staphylococus aureus y Echerichia coli; Como resultado, los metabolitos secundarios como flavonoides, compuestos fenólicos, esteroides y alcaloides tienen acción antibacteriana. La planta Piper aduncum L. (matico) es un buen agente curativo y antifúngico. Se comercializa como un producto farmacéutico en gel. La conclusión de que el aceite esencial de Piper aduncum L. (matico) no ayuda a prevenir, mucho menos eliminar el nuevo coronavirus y su composición química del matico solo ayuda a prevenir algunos de los síntomas de Covid 19.

Palavras-Chave: COVID-19; Piper aduncum L.; enzima; cicatrización; inhibición

\section{INTRODUCCIÓN}

A finales del año 2019, se corrieron las noticias de un brote de neumonía grave en la ciudad de Wuhan, provincia de Hubei, en China. Estudios epidemiológicos mostraron que la enfermedad rápidamente se expandía, atacando agresivamente adultos entre los 30 y 79 años, llegando a una letalidad global del $2.3 \%$ (1). Los primeros casos se reportaron en personas que trabajaban en Huanan Seafood Wholesale Market, mercado de comidas preparadas con productos extraídos del mar, pero también usaban carnes de animales silvestres $(2,3)$. Los estudios iniciales etiológicos dirigidos a los agentes de la infección respiratoria aguda, la influenza aviar, el síndrome respiratorio agudo severo (SARS, del inglés, Severe Acute Respiratory Syndrome) y el síndrome respiratorio del Medio Oriente (MERS, del inglés, Middle East Respiratory Syndrome), dieron resultados negativos. La información que se obtuvo gracias al aislamiento en cultivo de células, seguido de microscopía electrónica se demostró que era un nuevo agente viral, del grupo de los coronavirus. Esta enfermedad, conocida ahora como COVID-19 se propagó a los otros países asiáticos para luego llegar hasta los demás continentes (1,3). El 11 de marzo de 2020, la Organización Mundial de la Salud (OMS) declaró como una pandemia, incitando a todos los países tomar medidas drásticas evitando el mayor número de contagiados posibles $(4,5)$. A la fecha, junio del 2021 se han confirmado un alrededor de $182,651,733$ muertes y más de 700.000 pacientes recuperados, datos que cambian día a día en el sitio web de la OMS. Este virus llamado como síndrome respiratorio agudo severo tipo-2 (SARS-CoV-2), causante de Covid-19, taxonómicamente se ubica en la familia Coronaviridae (5), subdividiéndose en cuatro géneros: Alphacoronavirus, Betacoronavirus, Gammacoronavirus y Deltacoronavirus $(6,7)$. Varios síntomas de los cuatro géneros mencionados son a causa de enfermedades provocados por los animales domésticos, y por lo tanto podría decirse que es de interés veterinario (8). 




Figura 1. Árbol filogenético de los coronavirus que se encontraron en humanos (HCoV) resaltan de color azul, los coronavirus zoonóticos se muestran de color rojo, los que se encontraron en murciélagos de color verde, y otros coronavirus de animales en color negro.

\section{A MENERA DE METODOLOGÍA}

La Organización Mundial de la Salud define a la salud como: "un estado de completo bienestar físico, mental y social, y no solamente a las causantes por enfermedades". Posteriormente, la OMS (2020) frente a la pandemia que se está viviendo, definió a la medicina tradicional como "el conjunto de conocimientos, aptitudes y prácticas basados en teorías, creencias y experiencias indígenas de las diferentes culturas, sean o no explicables, así como para la prevención, el diagnóstico y el tratamiento de enfermedades físicas o mentales". La Ley $N^{\circ} 27300$, define como plantas medicinales "a aquellas cuya calidad y cantidad de principios activos tienen propiedades terapéuticas comprobadas científicamente en beneficio de la salud humana". Asimismo, el inventario de plantas medicinales debe estar aprobado por el Ministerio de Salud, el Instituto Nacional de Medicina Tradicional (ahora el CENSI), el Instituto Nacional de Investigación Agraria (INIA), el Colegio Químico Farmacéutico del Perú y el Colegio de Biólogos del Perú. 
A raíz de la pandemia provocado por el COVID-19, las publicaciones que se compartieron por muchos usuarios de las redes sociales a finales del año 2020 aseguraban que el consumo del matico puede prevenir y probablemente eliminar los síntomas del coronavirus. Hoy en día el reino vegetal es considerado fuente de medicamentos frente a las nuevas enfermedades que se puedan avecinar. Las plantas medicinales desde la antigüedad son usadas como medicamentos por los pobladores para combatir las enfermedades que afectan al cuidado de su salud. Se cree que las posibles soluciones para frenar muchas enfermedades se encuentran de manera oculta en los componentes de las pantas medicinales. Hablando de una ellas como con el Piper aduncum L Hope, vulgarmente llamado matico, a esto se le puede sumar los rumores que se hicieron respecto al Eucalyptus camaldulensis que también se dijo que podría prevenir los síntomas del nuevo coronavirus. La presente investigación representa el resumen de muchos trabajos de investigaciones anteriores, con respecto al Piper aduncum L, composición química, actividad antimicrobiana y los posibles efectos significativos frente al Sars CoVID-19.

\section{Matico (Piper aduncum L.)}

Matico (Buddleja globosa Hope) es una planta oriunda de Chile, Argentina y Perú, pero en este último país se le conoce como matico a la especie Piper angustifolium (Piperaduncum), que abunda mayormente de manera silvestre en toda la selva peruana. En Chile, matico ( $B$. globosa) crece de forma silvestre en los cerros y quebradas, hasta los 2.000 metros de altitud $(9,10)$. En el Perú, el Matico se distribuye en los departamentos de Amazonas, Ayacucho, Loreto, Madre de Dios, Puno, San Martin, Ucayali, Cajamarca, Lambayeque, Pasco y Piura (11). Así como en la sierra baja abrigada de los valles interandinos entre los 2600 -2700 msnm de Cajamarca, Cuzco, Junín, Lima, Huánuco (12). B. globosa es un arbusto que en la mayor parte de su vida se mantiene verde, puede alcanzar hasta los cuatro metros de altura. Sus tallos son subleñosos, de manera ramificada desde la base; sus hojas pueden llegar a medir hasta $20 \mathrm{~cm}$ de largo, lanceoladas, de color verde oscuro y rugosas en su superficie. Sus flores son pequeñas, hermafroditas, de color amarillas agrupada en cabezuelas esféricas pueden medir hasta dos centímetros (FIGURA 2). En la temporada de primavera a verano se les puede observar en floración repleta de semillas muy pequeñas que se esparcen con la ayuda del viento para su futura propagación (10). 


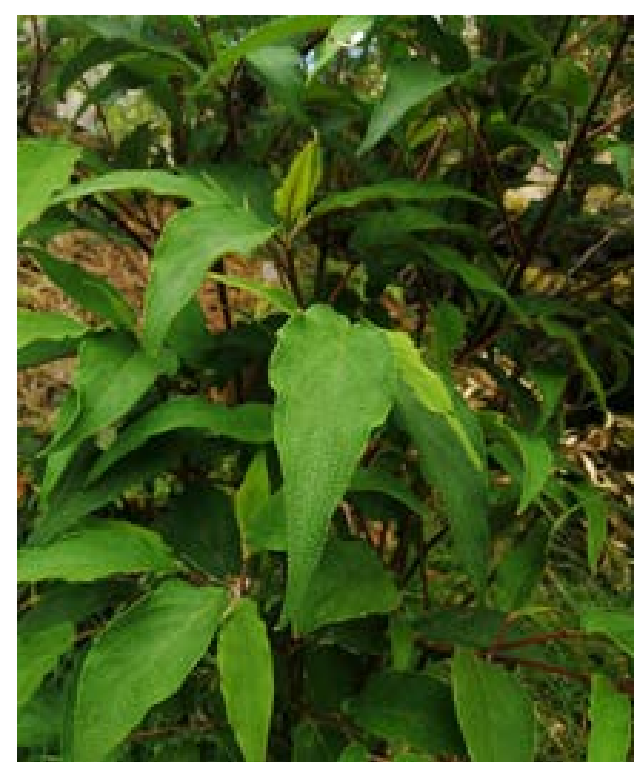

Figura 2. Piper aduncum L. (matico) en el valle del Mantaro distrito de Mariscal Cáceres, provincia y región de Huancavelica - Perú.

Piper aduncum L., aplicación tradicional y contemporánea

Se conoce que el género Piper cuenta con aproximadamente cien especies, entre árboles y arbustos, distribuidos en Asia, África y América (13). El uso que se le dé a esta planta es muy variado, desde la curación de heridas hasta las úlceras, mediante la aplicación de hojas y tallos molidas, o en infusión de las hojas previamente deshidratadas para combatir el dolor de hígado y la de vesícula, las dolencias internas, úlceras en el estómago, la sarna y sífilis $(14,15)$.

Su componente más importante por el que se atribuye en parte sus virtudes cicatrizantes, es el tanino (polifenol natural), tiene una concentración de $5.7 \%$ y además de numerosos glucósidos, especialmente de tipo flavonoides (luteolina, luteolina 7-glucósido, linarina y derivados del ácido cafeico) con propiedades antioxidantes y protectoras de la membrana celular; también ácido artánico, resinas, esteroles, éster de ácido graso fenólico, terpenos y saponinas (17-19).

El Matico presenta como compuesto principal a la Canfora (22.68\%), Canfene (21.18\%) e Isoborneol (11.53\%); también contiene alfa pineno, mirceno, limoneno, borneol y terpinol acetato. El aceite esencial contiene 5-metoxi-6(2'-propen)-benzodioxole, dillapiol, etoxidillapiol, mirisicina y piperitona (16).

Su uso tradicional es múltiple, siendo empleada principalmente para aliviar enfermedades del tracto respiratorio (antiinflamatorio, antitusígeno y antiséptico), para dolencias gastrointestinales (diarreas, disentería), para la desinfección de heridas externas y para evitar infección microbiana en niños con desnutrición (17) Además, posee propiedades astringentes y se utiliza para detener 
hemorragias y aliviar ulceras. Es muy efectiva para aliviar las náuseas, el dolor de estómago, el vómito y para casos de resfríos, tos, bronquitis, neumonía y otros problemas respiratorios (18). Piper aduncum también es usado debido a sus actividades biológicas como antioxidante, hepatoprotector, antialérgico, antitrombótico, anticancerígeno, antibacteriano, antifúngico, entre otras
$(19,20)$. Se le considera también diurética $(21)$. Según diversos estudios, los péptidos activos y proteínas derivadas de esta planta tienen efectos beneficiosos para la cicatrización y curación de heridas agudas y crónicas. Asimismo, se ha demostrado un efecto antisecretorio y gastroprotector al evaluar el extracto etanólico y metanólico $(22,23)$.

Tabla 1. Plantas medicinales usadas para las enfermedades respiratorias agudas (entre ellas Covid-19) según entrevistas a líderes indígenas (marzo 2021).

\begin{tabular}{|c|c|c|c|c|}
\hline & Plantas & Observaciones & Modo de uso & Efecto \\
\hline \multirow[t]{8}{*}{$\begin{array}{l}\text { Uso y } \\
\text { eferencia } \\
\text { frecuente }\end{array}$} & Boains (Mucura) & $\begin{array}{l}\text { Hay } 2 \text { tipos de hojas } \\
\text { grandes y pequeñas }\end{array}$ & $\begin{array}{l}\text { Inhalación de vapor/ } \\
\text { baños sahumerios para } \\
\text { fumigación }\end{array}$ & Mejora la respiración \\
\hline & $\begin{array}{l}\text { Mucura + hojas de } \\
\text { ayahuasca }\end{array}$ & & Brebaje & Mejora la respiración \\
\hline & $\begin{array}{l}\text { Hojas de Mucura + } \\
\text { ajo +kion }\end{array}$ & & Brebaje & Mejora la respiración \\
\hline & Matico+limón+kion & & Vaporización/brebaje & $\begin{array}{l}\text { Mejorado los síntomas } \\
\text { del Covid } 19\end{array}$ \\
\hline & & & & Mejora la respiración \\
\hline & $\begin{array}{l}\text { Matico en } \\
\text { combinación con } \\
\text { otras plantas } \\
\text { (sacha ajo, kion, } \\
\text { limón, mucura, } \\
\text { cebolla, manzanilla, } \\
\text { eucalipto, hierba } \\
\text { luisa, otros) }\end{array}$ & Hervir & Vaporización/brebaje & $\begin{array}{l}\text { Mejorado los síntomas } \\
\text { del Covid } 19 \\
\text { Mejora la respiración }\end{array}$ \\
\hline & $\begin{array}{l}\text { Limón + miel de } \\
\text { abeja + ajo + cebolla }\end{array}$ & & Brebaje & Alivia la tos \\
\hline & Piñón colorado & & $\begin{array}{l}\text { Baños/inhalación de } \\
\text { vapor }\end{array}$ & Baja la fiebre \\
\hline
\end{tabular}




\begin{tabular}{|c|c|c|c|c|}
\hline & Plantas & Observaciones & Modo de uso & Efecto \\
\hline \multirow{10}{*}{$\begin{array}{l}\text { Uso y } \\
\text { referencia } \\
\text { esporádica }\end{array}$} & Cético & Hacer hervir la corteza & $\begin{array}{l}\text { Baños/inhalación de } \\
\text { vapor }\end{array}$ & $\begin{array}{l}\text { Broncodilatador y } \\
\text { desinflamatorio }\end{array}$ \\
\hline & Corteza de cedro & Hervir & $\begin{array}{l}\text { Baños/inhalación de } \\
\text { vapor }\end{array}$ & \\
\hline & Malva & & $\begin{array}{l}\text { Baños/inhalación de } \\
\text { vapor }\end{array}$ & Para la fiebre \\
\hline & Resinas de catahua & & & \\
\hline & $\begin{array}{l}\text { Semilla de sandía y } \\
\text { zapallo }\end{array}$ & Se tritura y se toma & & \\
\hline & $\begin{array}{l}\text { Macerados en } \\
\text { bebidas alcohólicas }\end{array}$ & & & \\
\hline & Chirisanango & & $\begin{array}{l}\text { Beber el zumo de las } \\
\text { hojas chancadas }\end{array}$ & \\
\hline & Corteza de lacre & & & \\
\hline & $\begin{array}{l}\text { Jugo de coco con } \\
\text { azúcar rubia }\end{array}$ & Hervir & Tomar & \\
\hline & Manteca animal & & Ingesta por 3 días & Quita la tos \\
\hline
\end{tabular}

En la tabla se describe sobre las plantas medicinales usadas para las enfermedades respiratorias agudas como el Covid-19

Composición química del Piper aduncum L.

Se han identificado una serie de compuestos químicos en B. globosa, que varían dependiendo del órgano de la planta estudiado. Una completa revisión de los compuestos identificados fue publicada por Houghton (14) una década atrás y puede ser revisada para mayor detalle. En el matico se han identificado heterósidos feniletanoides, flavonoides y terpenoides (iridoides, sesquiterpenos, diterpenos y triterpenos). Las hojas, tallos y partes leñosas contienen gran cantidad de los iridiodes aucubina y catalpol y estructuras relacionadas; verbascósido (feniletanoide glicosilado), diversos flavonoides (acacetina7-O-rutinósido, apigenina, escutelareína, quercitina), sesquiterpenos (budledinas A, By C, dihidrobudledina $A$, budledona By zerumbona), diterpenos (budlejona y estructuras relacionadas), el bisditerpeno maytenona $(24,25)$ y los triterpenos a y b-amirina. En las flores, en tanto, se han identificado los 
triterpenoides lupeol, b-amirina y glutinol; flavonoides como luteolina e hidroxiluteolina; y el esterol condrilasterol $(26,24,27)$.

\section{Ficha monográfica del matico (Piper aduncum $\mathrm{L}$.)}

- Nombre científico: Piper aduncum L.

- Nombres vernáculos: Matico, matico chileno, pañil, palguín.

- Categoría:Plantamedicinal,omedicamento herbario tradicional (Resolución Exenta $\mathrm{N}^{\circ}$ 548, Ministerio de Salud de Chile, 27/07/2009).

- Droga vegetal: Hoja desecada (Piper aduncum $\mathrm{L}$ ).

- Usos tradicionales:

- Preparación: infusión de hojas secas.

- Uso interno: úlceras digestivas, indigestión, dolor de estómago, disfunción hepática.

- Uso externo: vulnerario, traumatismos y heridas de la piel.

- Principales constituyentes: Flavonoides (quercetina, acacetina-7-0-rutinósido, apigenina, escutelareína, luteolina, hidroxiluteolina) Carotenoides (crocetina) Feniletanoide glicosilado (verbascósido) Diterpenos (budlejona y estructuras relacionadas) Bisditerpeno (maytenona) Triterpenos ( $a$ y b-amirina, lupeol, glutinol), Sesquiterpenos (budledinas $A$, $B, C$; dihidrobudledina $A$, budledona $B$, zerumbona) Esterol (condrilasterol).
- Acciones farmacológicas (demostradas in vitro): Vulnerario (cicatrizante), Antioxidante, Antiinflamatorio y analgésico, Gastroprotector, Antibacteriano y antifúngico.

- Estudios clínicos: No existen estudios clínicos publicados a la fecha.

- Reacciones adversas: No descritas

- Contraindicaciones: No descritas

- Interacciones farmacológicas: No descritas

- Toxicidad:

- Se considera libre de toxicidad.

- Toxicidad aguda in vivo: extracto etanólico de hojas, sin toxicidad en ratones.

- Citotoxicidad in vitro: extracto etanólico de hojas, citotóxico a concentración 10 veces superior a la concentración necesaria para inducir proliferación de fibroblastos humanos.

\section{DESARROLLO Y DISCUSIÓN}

\section{Acciones farmacológicas}

Las propiedades farmacológicas de Piper aduncum $L$ fueron estudiadas por diversos investigadores, para explicar los usos que se dé al matico.

\section{Efecto cicatrizante}

La pérdida de la barrera protectora en la piel puede llegar a tener consecuencias graves 0 incluso la muerte, según su extensión o complicaciones agregadas y 
no controladas. La reparación del tejido cutáneo permite restaurar la función de barrera de la piel. Varios compuestos de Piper aduncum L, actuarían en diferentes fases de la cicatrización, como en la fase de regeneración al estimular la proliferación de los fibroblastos, y en la inflamación local que, al ser regulada, permitiría acelerar y facilitar la cicatrización $(27-29,32,33)$ demostraron que concentraciones de 50 a $100 \mu \mathrm{g} / \mathrm{mL}$ de extracto acuoso de hojas frescas de B. globosa los resultados muestran que el contenido de polifenoles de B. globosa son capaces de mejorar la capacidad de contracción y de reorganización de las fibras de colágeno en la fase final de la cicatrización, con importantes consecuencias de restauración de la funcionalidad y cosméticas.

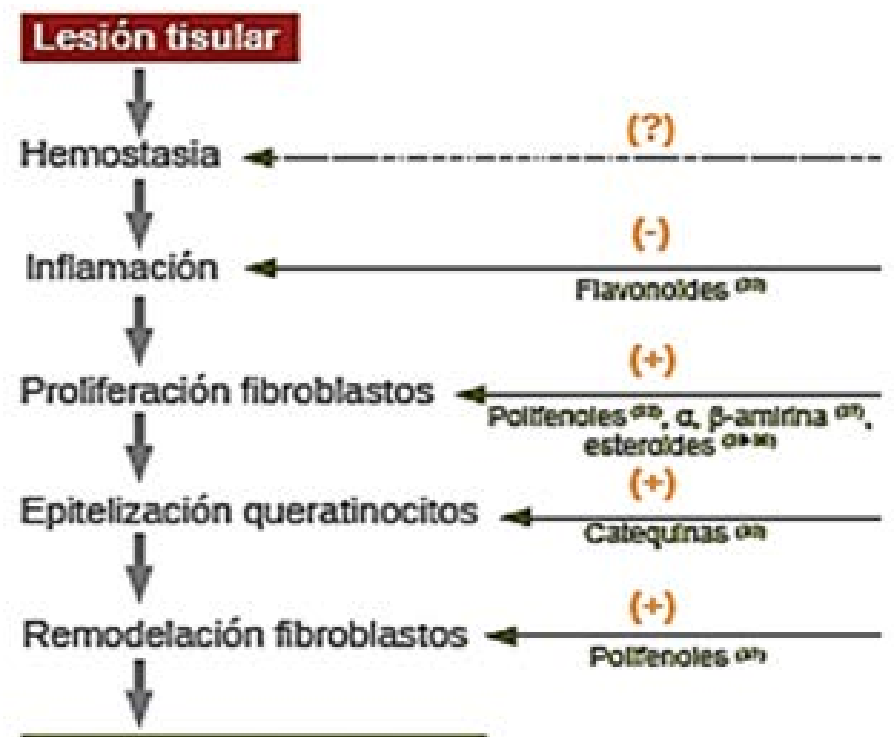

Tejido sano $/$ cicatrizado

Figura 3. Esquema que resume los sitios putativos de acción y los compuestos responsables de la acción vulneraria de la hoja de matico (Piper aduncum L.).

\section{Efecto antimicrobiano y antifúngico}

El verbascósido presente en las hojas de Piper aduncum L. posee actividad antimicrobiana (30). También se dijo que el verbascósido inhibiría la vía metabólica de síntesis de proteínas al bloquear la entrada de leucina en Staphylococcus aureus (31).

Extractos lipofílicos obtenidos de la corteza de tallos de Piper aduncum L presentan actividad antifúngica contra Trychophyton y
Epidermophyton, en particular los compuestos buddlejona, maytenona, buddelinas A y B y deoxibuddlejona, en una concentración de 125 $\mu \mathrm{g} / \mathrm{mL}$, perdiendo su actividad a $1,0 \mathrm{mg} / \mathrm{mL}$ (32). Los sesquiterpenos buddelina A (IC50 43 $\mu \mathrm{M})$ y buddelina B (IC50 $51 \mu \mathrm{M})$ mostraron la mayor actividad antifúngica contra T. rubrum, $T$. interdigitale y E. floccosum, respecto de los demás compuestos probados. 
Recientemente se han ensayado las propiedades antibacterianas de otra especie de Piper aduncum L (B. saligna) contra un conjunto de bacterias Gram-positvas y Gramnegativas (33). Presentando mayor actividad que el extracto metanólico de hojas contra Bacillus cereus, Streptococcus pyrogens y Pseudomonas aeruginosa, el extracto no resulta tan eficaz como los antibióticos cloranfenicol y estreptomicina.

\section{Composición química del aceite esencial de Piper aduncum $L$.}

El contenido del aceite esencial de las hojas de Piper aduncum L. consiste en un $0,63 \%$ de compuestos terpenoides (34). Los monoterpenos componen el 53\% del aceite esencial y son representados por el linalol (mayor compuesto). Los sesquiterpenos conforman el 55\% del contenido del aceite esencial y son representados por diversos compuestos, especialmente el óxido de cariofileno, epóxido II de humuleno, (E) Nerolidol y a-Copaeno. También estaban presentes pequeñas cantidades de alil benzeno safrol y de metil cetona 2- Undecanona. La actividad antibacteriana del extracto etanólico de Piper aduncum sobre Streptococcus pyogenes mediante el método de Kirby Bauer y la determinación de la concentración inhibitoria (19). Al comparar los halos de inhibición según Durafford, se determinó que Streptococcus pyogenes fue sumamente sensible a todas las concentraciones con efecto similar a la penicilina. Estos resultados concuerdan con un estudio en el que se trabajó con la mezcla de Piper aduncum, Plantago mayor y Alternanthera philoxeroides(c.Mart) Griseb para evaluar su actividad antibacterial frente a Staphylococus aureus y Echerichia coli; obteniéndose como resultado que los metabolitos secundarios como flavonoides, compuestos fenólicos, esteroides y alcaloides cuentan con acción antibacterial.

En muchas investigaciones que se ha trabajado con aceites esenciales de plantas de la familia Piperaceae encontrando que presenta actividad antimicrobiana contra bacterias y hongos. La actividad antimicrobiana del extracto etanólico de Piper aduncum se debería a sus componentes activos (19). El tamizaje fitoquímico de Piper aduncum L. indica que este contiene una abundante cantidad de flavonoides, fenoles y taninos; moderada cantidad de azúcares y compuestos grasos; y leve cantidad de alcaloides, triterpenos y esteroides. Los beneficios para la salud de los flavonoides han sido bien reconocidos en varios estudios por su acción contra bacterias, protozoos e infecciones fúngicas, así como por contrarrestar la propagación y los efectos de las toxinas bacterianas. Los canales de iones son puntos especialmente sensibles de inhibición y posibles blancos de flavonoides, además de estar regulados por reacciones de fosforilación/desfosforilación. Los flavonoides también fortifican la conectividad de los tejidos mediante la inhibición de algunas de las enzimas que pueden hidrolizar el proteoglicano y la malla proteica, lo cual podría aumentar el efecto antibacteriano al obstaculizar la difusión de la infección al tejido (19). 


\section{Sin pruebas para el nuevo Coronavirus}

AFP Colombia Publicado el lunes 6 julio 2020 a las 16:57 Copyright AFP 2017-2021. Todos los derechos reservados. Se afirma públicamente que el matico no fue aprobado para tratar problemas respiratorios, ni COVID-19. Distintas publicaciones aseguraban que la planta de matico "abre milagrosamente los pulmones" que fueron compartidas cientos de miles de veces en redes sociales desde el pasado 1 de mayo del 2020 junto a una imagen de una planta y una receta para tratar a pacientes con COVID-19. Si bien esta planta es utilizada en la medicina popular, expertos y organismos de salud aseguran que no permite curar el nuevo coronavirus $u$ otros problemas respiratorios. Por otra parte, también mencionan que el Piper aduncum L no tiene aún investigaciones o datos reales que actúa como un antiviral, pues hoy en día estamos en plena lucha con un virus tal como lo mencionó también la OMS.

También que "aunque algunos remedios occidentales, tradicionales o caseros pueden proporcionar confort y aliviar los síntomas de la COVID-19, no hay pruebas de que los medicamentos actuales puedan prevenir o curar la enfermedad" (1). "Si tienen algún familiar o amigo que está con covid-19, que ya no puede respirar les recomiendo esta planta medicinal producto de la naturaleza creada por Dios se llama Matico (sic)", dice una de las publicaciones en Facebook, que también incluye una receta: "COMO SE PREPARA: coger 4 ramitas del matico más 3 limones al limón partirlo con toda la cáscara en cuatro partes, kion o jengibre y hacerlo hervir conjuntamente con el matico por espacio de 10 a 15 minutos, luego proceda a tomarse caliente una taza y vera los resultados (sic)".

Publicaciones similares con distintas imágenes de plantas, a la que también le han dado otros nombres como "acuyo", "hoja santa", "momo" o "cordoncillo", se han replicado al menos 122.000 veces en Facebook y en Twitter.

Matico es el nombre que se le da popularmente a dos plantas, una especie llamada Buddleja Globosa y otra denominada Piper aduncum, explican los especialistas. Sin embargo, coinciden en que suele asociarse el matico con la primera especie. La Buddleja Globosa crece en países como Argentina, Chile, Perú y Bolivia, sobre los 2.500 metros encima del nivel del mar (35), es un arbusto con hojas alargadas, "verde oscuras en la cara superior y plateadas en la inferior; cabezuelas de flores amarillo-anaranjadas, muy perfumadas", describe el Sistema de Información de Biodiversidad de Argentina. Allí también se detalla su uso: "En medicina popular se usa externa e internamente como desinfectante, vulnerario [NDLR: que cura las heridas o llagas], cicatrizante, hemostático [que detiene una hemorragia], antiinflamatorio". Esta planta recibe muchos nombres comunes, por ejemplo: cordoncillo, pañil, acuyo, deshinchadora, hierba del soldado, nativo, explicó Ramiro Fonnegra, doctor en Botánica de la Universidad de São Paulo, Brasil. Algunos de estos nombres aparecen en varias de las publicaciones virales. "A todas las especies del género les dan mismas propiedades medicinales, la mayoría de ellas 
sin verificación científica, solo las referencias tradicionales", detalló Fonnegra. Un libro de botánica almacenado en la Biblioteca Nacional de Chile ya explicaba en 1923 que en ese país tiene varios usos, para lavar las heridas, ayudar a la cicatrización, en úlceras del estómago o ataques al hígado. Sus propiedades han sido registradas por el Ministerio de Agricultura de Perú, la Universidad Nacional Mayor de San Marcos, de ese país, y el Centro Nacional de Información Biotecnológica de Estados Unidos. Las publicaciones incluyen fotos de diferentes plantas, muestran una especie denominada Piper aduncum, a la que a veces también llaman matico, especificó (35).

\section{¿Tratamiento para el daño pulmonar y Covid-19?}

Las publicaciones indican que el matico "abre milagrosamente los pulmones" y lo recomiendan para tratar a pacientes con Covid-19 "que ya no pueden respirar". Sin embargo, los expertos y organismos de salud coinciden en que no hay evidencia científica de que esa planta tenga capacidad expectorante o permita curar el nuevo coronavirus. Los principales síntomas del Covid-19 son fiebre, tos y "algunas personas pueden desarrollar formas más graves de la enfermedad, como la neumonía o dificultad respiratoria", según los Centros para la Prevención y el Control de Enfermedades de Estados Unidos (CDC) y la Organización Mundial de la Salud (OMS). Además, algunos pacientes pueden desarrollar infección respiratoria aguda grave (IRAG) $(4,5)$.
"No se aconseja el uso de ningún remedio herbal, o casero para las enfermedades respiratorias", sostuvo el médico Alejandro Oms, neumonólogo del Hospital Universitario Austral en Argentina y miembro de la Sección Infecciones de la Asociación Argentina de Medicina Respiratoria. "No hay evidencia de que esta planta u otras sirvan como broncodilatadores. Su eficacia es muy inferior a la que tienen los broncodilatadores farmacológicos. Usar estas plantas en virtud de que pueden curar es retrasar la consulta al médico y dejar que el cuadro de salud empeore por crear una falsa seguridad" (8).

Hasta el momento no hay documentación científica que ligue al matico con un alivio para los pulmones. "Hasta ahora no hay registros en revistas científicas sobre una capacidad expectorante de esta planta", afirmó. Y en relación al SARS-CoV-2, que provoca el Covid-19, explicó: "Este virus ha demostrado ser agresivo, letal, no creo que una simple mata pueda despejar los pulmones con una sola taza" (1).

Por su parte, indica que "aunque algunas soluciones de la medicina occidental o tradicional o remedios caseros pueden resultar reconfortantes y aliviar los síntomas leves de la COVID-19, hasta ahora ningún medicamento ha demostrado prevenir o curar esta enfermedad", y no recomienda automedicarse (8).

Los expertos consultados por la AFP también hicieron un llamado a no automedicarse, especialmente usando plantas medicinales que en un principio pueden aliviar 
algunos síntomas, pero que también "pueden tener otros principios o elementos que pueden causarle problemas al cuerpo humano. Con el desconocimiento que tenemos ahora del virus, podría ser peligroso", enfatizó también: "Las plantas medicinales no reemplazan las indicaciones de un médico para tratar una enfermedad" (1).

En verificaciones anteriores, la AFP ya ha confirmado que ni el jengibre, limón ni los vahos son efectivos contra el Covid-19. Respecto del jengibre, los especialistas consultados por AFP Factual explicaron en esta verificación que esta raíz no sirve como cura para la enfermedad. La especialista en inmunología María Rosa Bono, docente de la Facultad de Ciencias de la Universidad de Chile, indicó que, aunque el jengibre "inhibe respuestas inflamatorias o alergias", no se recomienda para evitar una infección viral. En cuanto al limón Cristian Paredes, docente del Internado de Farmacia Clínica en la Universidad Católica de Chile, explicó "que es una fruta cítrica que tiene un contenido importante de vitamina C, la que en la cultura colectiva se asocia a las defensas en temporadas de invierno. Sin embargo, diversos estudios han demostrado que no es así y su utilidad es netamente clínica en contextos muy limitados". En resumen, aunque el matico sea una planta utilizada en la medicina popular, expertos aseguran que no permite curar el nuevo coronavirus $u$ otros problemas respiratorios. Esta verificación fue realizada con base en la información científica y oficial sobre el nuevo coronavirus disponible a la fecha de esta publicación $(9,10)$.
De momento, "no hay ningún medicamento antiviral específico para prevenir o tratar el COVID-2019, pero es recomendable las vacunas que hasta el momento funciona de manera correcta y los datos de contagio bajaron significativamente" (8).

\section{CONCLUSIÓN}

Se concluye mencionado que el SARSCOVID-19 es un virus peligroso que se propaga rápidamente, hasta hoy no hay ningún tratamiento específico para lidiar con la enfermedad COVID-19. Tomando en cuenta que, el uso y consumo de Piper aduncum $L O$ más conocido como matico no ayuda prevenir ni mucho menos el contagio, más aún se hace un mal uso de estas plantas medicinales, las características mencionadas del Piper aduncum $L$ solo es un cicatrizante $y$ antimicrobiana como también antifúngico pero no es un antiviral, y más aun no nos ayuda si el virus está en constante evolución, haciendo que los efectos medicinales de algunas plantas que puedan ayudar a prevenir algunas de sus síntomas de esta manera las plantas son cada vez menos eficientes, las vacunas que hoy en día se está usando en los hospitales no son efectivas que puedan eliminar el virus, es muy probable que los protocolos de seguridad social continúe hasta 2022. En Perú, en los años de 2020 se manifestaron algunos pobladores denominados Comando Matico (35), a raíz de ello la planta se hizo viral en las redes sociales, pero para la triste verdad no fueron muy efectivas y afectaron a una gran cantidad de 
los pobladores (36). Por lo tanto, se aconseja continuar contodas las restricciones decretadas por el estado hasta que se logre una completa vacunación de la población en general. Estos resultados representan como la base para las futuras investigaciones y aplicaciones de Piper aduncum $L$ en las enfermedades que podría avecinarse en un futuro.

\section{REFERENCIAS BIBLIOGRÁFICAS}

1. Wu Z, McGoogan JM. Characteristics of and important lessons from the coronavirus disease 2019 (COVID-19) outbreak in China: Summary of a report of 72314 cases from the Chinese Center for Disease Control and Prevention. JAMA. 2020.

2. Khan $S$, Siddique R, Adnan-Shereen $M$, Ali A, Liu J, Bai Q, et al. The emergence of a novel coronavirus (SARS-CoV-2), their biology and therapeutic options. J Clin Microbiol 2020. [Epub ahead of print]. 202011 de marzo.

3. Guo YR, Cao QD, Hong ZS, Tan YY, Chen $\mathrm{SD}$, Jin $\mathrm{HJ}$, et al. The origin, transmission and clinical therapies on coronavirus disease 2019 (COVID-19) outbreak - an update on the status. 2020, p. 7:11.

4. Adhanom-Ghebreyesus T. General's opening remarks at the media briefing on COVID-19 11 March 2020. 20204 de abril.

5. Gorbalenya AE, Baker SC, Baric RS, de Groot RJ, Drosten C, Gulyaeva AA, et al. The species severe acute respiratory syndrome-related coronavirus: classifying 2019-nCoV and naming it SARS-CoV-2. 2020; 5: p. 536-544.

6. Pal M, Berhanu G, Desalegn C, Kv R. Severe acute respiratory syndrome coronavirus-2 (SARS-CoV-2): An update. 2020: p. 12:e7423.

7. Chan JF-W, Kok K-H, Zhu Z, Chu H, To KKW,
Yuan S, et al. Genomic characterization of the 2019 novel human-pathogenic coronavirus isolated from a patient with atypical pneumonia after visiting Wuhan. 2020: p. 9:221-236.

8. American Veterinary Medical Association (AVMA). Coronavirus: Detailed taxonomy. Schaumburg, IL: AVMA; en, 2020. 20204 de abril.

9. Montes M, Wilkomirsky T. Medicina Tradicional Chilena. 1987.

10. Vogel H, Razmilic I, San Martín J, Doll U, González B. Plantas medicinales chilenas: Experiencia de domesticación y cultivo de boldo, matico, bailahuén, canelo, peumo y maqui.: Editorial Universidad de Talca; 2005.

11. Flores $K$, Puente $M$. Perú: Universidad Peruana Los Andes; 2016.

12. Morocco S. Caracterización microhistologico, físico y químico del aceite esencial de las hojas de matico (Piper aduncum), extraído por arrastre de vapor en un equipo modular. [Tesis para optar el grado de Título Profesional de Ingeniero Químico] Perú: Universidad Nacional del Altiplano - Puno; 2017.

13. Linnaeus C. Species plantarum Reedición EE. UU: Ed. Create Space Independent Publishing Platform; 2012.

14. Baeza V. Los nombres vulgares de las plantas silvestres de Chile y su concordancia con los nombres científicos. 1930: p. 118.

15. Muñoz M, Barrera E, Meza I. El uso medicinal y alimentación de plantas nativas y naturalizadas en Chile. Chile: Publicación Ocasional $N^{\circ}$ 33, Chile: Museo Nacional de Historia Natural; 1981.

16. Quiñones D, Aranzábal G, Verástegui A, et al. Efecto del extracto acuoso de Piper elongatum Vahl (matico) sobre la motilidad intestinal en ratones cuba: Revista Cubana de Farmacia.; 2016. 
17. Rengifo R. Efecto del extracto etanólico de las hojas de Piper aduncum, procedente de Otuzco y Trujillo en la oxidación de la LDL humana, in vitro. UCV - Scientia 11(1); 2019.

18. López P. Estudio de las características fisicoquímicas y fitoquímicas de las hojas de Piper acutifolium Ruiz \& Pav. (matico). Tesis para optar el título profesional de Químico farmacéutico. Facultad de Ciencias de la Salud. Escuela profesional de farmacia y bioquí Universidad Católica Los Ángeles, Chimbote, Perú; 2018.

19. Benites Rodríguez Alondra. Efecto bactericida in vitro de Piper aduncum sobre Streptococcus pyogenes. Tesis para Optar el Grado de Bachiller en Medicina. Facultad de Medicina. Universidad Nacional de Trujillo.; 2017.

20. Lago, Joao Henrique $G$, Chen $A M$, et al. Prenylated benzoic acid derivatives from Piper aduncum $L$. and $P$. hostmannianum $C$. DC. (Piperaceae): In Phytochemistry Letters 2; 2009.

21. Abreu Guirado, O., Ana A. Rodríguez, Maybel Morgado Montes, y Laura B. Cao Vocero. Farmacognosia, farmacobotánica, farmacogeografía y farmacoetimología del platanillo de Cuba (Piper aduncum subespecie ossanum) Ciudad de la Habana: Revista Cubana de Plantas Medicinales; 2012.

22. Salud INd. Documento Técnico: Diálogo Intercultural en Salud Lima, Perú; 2014.

23. Huamán, J.; Raez, E.; Quino, M. y Rodríguez, J. Efecto gastro protector y antisecretor de un fitofármaco de hojasde matico (Piper aduncum). Revista Peruana de Medicina Experimental y Salud Publica; 2013.

24. Houghton PJ. Buddleja globosa: a medicinal plant of Chile, their chemistry, biological activity and traditional uses Chile: BLACPMA; 2003.

25. Houghton $P$, Mensah A. Biologicallyactive compounds from Buddleja species.
Romeo JT, Ed. Human Health protection, nutrition and plant defense: Recent advances in Phytochemistry: Phytochemicals: New York: Kluwer Academic/Plenum; 1999.

26. Vogel H, Razmilic I, San Martín J, Doll U, González B. Plantas medicinales chilenas: Experiencia de domesticación y cultivo de boldo, matico, bailahuén, canelo, peumo y maqui Talca: Editorial Universidad de Talca; 2005.

27. Liao $\mathrm{YH}$, Hougthon PJ, Bloomfield $\mathrm{S}$, Vlientinck A, Vanden-Berghe D. Know and novel constituents from Buddleja species and their activity against leukocyte eicosanoid generation.: J Nat Prod; 1999.

28. Houghton PJ. Buddleja globosa: a medicinal plant of Chile, their chemistry, biological activity and traditional uses.: BLACPMA; 2003.

29. Houghton PJ, Hylands $P J$, Mensah AY, Hensel A, Deters AM. In vitro tests and ethnopharmacological investigations: Wound healing as an example: J Ethnopharmacol; 2005.

30. Pardo F, Perich F, Villarroel L, Torres R. Isolation of verbascoside,an antimicrobial constituent of Buddleja globosa leaves: J Ethnopharmacol; 1993.

31. Ávila JG, de Liverant JG, Martínez A, Martínez G, Muñoz JL, Arciniegas A, Romo de Vivar A. Mode of action of Buddleja cordata verbascoside against Staphylococcus aureus: J Ethnopharmacol; 1999.

32. Mensah AY, Houghton P, Blommfield $S$, Vlietinck A, Vanden Berghe D. Know and novel terpenes from Buddleja globosa displaying selective antifungal activity against dermatphytes: J Nat Prod; 2000.

33. Adedapo AA, Jimoh FO, Koduru S, Masika PJ y Afolayan A. Assessment of the medicinal potentials of the methanol extracts of the leaves and stems of Buddleja saligna. 2009; p. 9: 21. 
34. S. Dousseau, Izabel de Souza Chaves, Evaristo Mauro de Castro, Amauri Alves de Alvarenga, Eduardo Alves, José Eduardo Brasil Pereira, Jessé Marques da Silva Junior \& Vanessa Bastos Pereira. Description of the limbo of Piper aduncum L. (Piperaceae): Structural analysis, histochemical and essential oils.: Gayana Bot.; 2014.

35. Lucila Pautrat O. María Pía Sembrero $H$. y Policarpo Sánchez. El comando matico: estrategia de autodefensa de los pueblos indígenas frente a la pandemia por Covid-19 Lima, Perú: Primera edición digital, Lima marzo de 2021; 2021.
36. Prieto Vidal N, Adeseun Adigun O, Pham T. y Col. Los efectos de la saponificación en frío sobre la composición de ácidos grasos no saponificados y la percepción sensorial de los jabones de hierbas naturales comerciales: Moléculas, 23; 2018.

Conflicto de intereses: Ninguno declarado por los autores. Financiación: Ninguna declarada por los autores.

Agradecimiento: Ninguno manifestado por los autores

\section{ACERCA DE LOS AUTORES}

Franklin Ore Areche. Ingeniero Agroindustrial, Universidad Nacional de Huancavelica. Perú. Magíster en Agronegocios y Comercio Internacional. Docente en la Universidad Nacional de Huancavelica, Escuela Profesional de Ingeniería Agroindustrial. Universidad Nacional de Huancavelica, Perú.

Alfonso Ruiz Rodríguez. Ingeniero en industrias alimentarias, Universidad Nacional del Centro del Perú. Magíster en investigación científica. Docente superior, Universidad Nacional de Huancavelica, Perú.

Jovencio Ticsihua Huaman. Ingeniero Agroindustrial. Universidad Nacional de Huancavelica, Perú.

Denis Dante Corilla Flores. Ingeniero en Industrias Alimentarias, Universidad Nacional del Centro del Perú. Magister en Tecnología y Gestión de la Calidad en Alimentos. Catedrático de Matemática e Ingeniería de alimentos, Escuela Profesional de Ingeniería Agroindustrial de la Universidad Nacional de Huancavelica, Perú. 